\title{
Apoptosis of Oligodendrocytes and Post-Translational Modifications of Myelin Basic Protein in Multiple Sclerosis: Possible Role for the Early Stages of Multiple Sclerosis
}

\author{
Artemios K. Artemiadis Maria C. Anagnostouli \\ Immunogenetics Laboratory of Department of Neurology, Aeginition Hospital, Athens Kapodistrian National \\ University Medical School, Athens, Greece
}

\section{Key Words}

Apoptosis $\cdot$ Oligodendrocytes $\cdot$ Post-translational modifications $\cdot \mathrm{MBP}$ molecule $\cdot$ Autoimmunity $\cdot$ Multiple sclerosis

\begin{abstract}
Recent studies outline apoptosis of oligodendrocytes (OLDs) as an early event prior to the formation of the demyelinated plaque and post-translational modifications (PTMs) of myelin basic protein as characteristic processes of normal-appearing white matter in multiple sclerosis (MS). We reviewed reports using the following keywords: apoptosis, PTMs, autoimmunity and multiple sclerosis in all possible combinations. Introductory basic scientific information is included for the non-experts. Given the standard and ongoing studies, we raise the hypothesis that, at least in some cases, defective apoptosis of OLDs, early in the course of the disease, and post-translationally modified molecules lead to the activation of immune responses and eventually to autoimmunity. Autoimmune reactions and epitope spreading that take place in the course of the disease might obscure the initial events and leave most investigators blind to etiopathogenesis. Our paper outlines the need for studies at the very ear-
\end{abstract}

ly stages of the disease, as well as sequential ones, in order to give us a valuable hint about the clarification of the cause(s) of the different clinical subtypes of MS.

Copyright $\odot 2010$ S. Karger AG, Basel

\section{Introduction}

Multiple sclerosis (MS) is a chronic inflammatory demyelinating disease of the central nervous system (CNS) affecting mainly young adults between 20 and 40 years of age [1]. Demyelination is mainly attributed to autoimmune mechanisms mediated by autoreactive $\mathrm{T}$ cells primed in the periphery by unknown autoantigens [2]. The hallmark of MS pathology is demyelinating plaque, characterized by infiltration of inflammatory cells, destruction of myelin, periplaque remyelination and, finally, formation of the astroglial scar [3]. Active inflammatory lesions in the CNS are responsible for the acute neurological symptoms in the relapsing-remitting form of MS. In progressive forms of MS, primary or secondary, diffuse neurodegeneration is more prominent than focal inflammation and patients suffer greater disability.

\section{KARGER}

Fax +41613061234 E-Mail karger@karger.ch www.karger.com
Maria C. Anagnostouli, MD, $\mathrm{PhD}$

Immunogenetics Laboratory of Dept. of Neurology, Aeginition Hospital Vassilisis Sofias Ave. 72-74

GR-115-28 Athens (Greece)

Tel. +30 210728 9165, Fax +30210685 2366, E-Mail managnost@ med.uoa.gr 
Although, the etiopathogenesis of MS is widely considered to be primary immunological, studies have shown that early neurodegenerative processes in normal-appearing white matter (NAWM) precede autoimmune mechanisms. Nonconventional imaging techniques have revealed diffuse metabolic instability in NAWM $[4,5]$. An autopsy study from Barnett and Prineas [6] has shown that apoptosis of oligodendrocytes (OLDs) occurs prior to the formation of the demyalinating plaque. In addition, a biochemical study of NAWM in MS, by Moscarello et al. [7], has examined the presence of post-translational modifications (PTMs) of the myelin basic protein (MBP) molecule.

These scientific observations were intriguing enough to search Medline using all possible combinations of the following keywords: multiple sclerosis, apoptosis, PTMs and autoimmunity. In this review we will provide some introductory information for the non-experts and we will try to synthesize the data for the pathogenesis of MS and a link to autoimmunity.

\section{Apoptosis}

Programmed Cell Death: A 'Silent' Suicide of Cells

Apoptosis or programmed cell death is an ATP-dependent physiological process, which is important for embryogenesis, tissue homeostasis and pathological conditions, such as infections and autoimmunity [8]. The major morphological changes of the apoptotic cell are cell shrinkage, chromatin aggregation, nuclear condensation and the disassembly of the cell into membrane blebs, called apoptotic bodies, without the loss of membrane integrity [8]. Membrane blebs are actually subcellular particles, the final products of the apoptotic cell degrading process, containing nuclear and cytoplasm remnants, that are transferred to the cell membrane [9]. Caspases (cysteinyl-aspartate-specific proteinases) are the main effectors of the apoptotic pathways [10].

There are 2 apoptotic pathways: the extrinsic and the intrinsic, the full description of which is beyond the scope of this review. Generally, in the extrinsic pathway, apoptosis is induced by death receptor/death ligand systems such as Fas (or CD95 or APO-1)/FasL [8]. The intrinsic pathway is stimulated by cytosolic stress signals (through BCL-2 family members such as Bid, Bad, Bim) that alter the permeability of mitochondria to cytochrome $\mathrm{C}$ and other apoptotic factors, which then contribute to the formation of apoptosome and the activation of the caspase system [8].
Rapid and early removal of self-debris is directed by early changes of the apoptotic cell surface that precede the release of its intracellular contents and/or the formation of apoptotic bodies (late stages of apoptosis). Apoptotic cells are phagocytosed by professional phagocytes, such as macrophages and immature dendritic cells and nonprofessional cells such as microglia in the CNS, that express receptors for specific membrane molecules on the apoptotic cell $[11,12]$. Opsonization molecules, such as complement $\mathrm{C} 3 \mathrm{~d}$, and antibodies are also crucial for clearance mechanisms [11, 12].

Unlike necrosis, clearance of apoptotic cells is a noninflammatory and immunosuppressive process. In apoptosis, the anti-inflammatory cytokines TGF- $\beta$ and IL-10 are secreted by phagocytes and apoptotic cells $[11,13]$. Tolerance is induced because self-peptides are presented in the MHC I and II molecules by the immature dendritic cells to $\mathrm{T}$ cells in a noninflammatory context and in the absence of co-stimulatory molecules like CD40 and CD40L [11].

\section{Apoptosis of OLDs in MS}

Recently, Barnett and Prineas [6] observed that OLD apoptosis and microglial activation are initial events prior to infiltration of macrophages and T cells and the formation of the demyelinating plaque. They studied cases with disease duration less than a few months (except one with 12 years) and they analyzed the pathological events of plaques of just a few hours old for the first time. It is reported that the most 'acute' plaques studied prior to their study were 7 days old. Components of the complement system were also apparent at early stages. Apoptosis is followed by phagocytosis of OLDs by activated microglia and rapid infiltration of macrophages that uptake myelin sheaths in the presence of $T$ cells. One unexplained finding is the presence of perivascular cuffs of mononuclear cells in areas usually affected at the beginning of the disease, which are distinct from areas where apoptosis of OLDs is present. Although these findings have not been widely confirmed and they are based on few patients, we consider them very important for two reasons: (1) the patients suffered from the disease for only a few months, so they were more likely to be in the primary etiopathogenic stage of the disease, meaning closer to the etiologic factor, and (2) the plagues were a few hours old.

An autopsy study of 6 cases with recent onset MS has interesting findings [14]. The predemyelinating plaques, isolated from NAWM, appear to be well-developed inflammation processes limited to Virchow-Robin spaces 
(perivascular cuffs) and around arterioles in the subependymal and subpial white matter, while there is no evidence of blood-brain barrier leakage. Myelin in these lesions is relatively preserved and microglia is activated containing myelin inclusion bodies positive for MBP. Most importantly, $\mathrm{T}$ cells and macrophages are scarce and do not differ from controls. Interestingly, C3d-IgG immune complexes are localized on microglial cells. The latter has also been confirmed by another study of NAWM in early MS cases [15]. The similarities with the Barnett and Prineas study are remarkably obvious. The immune system does not seem to be the primary culprit for myelin destruction, but instead the reactive component of a degrading process within the brain parenchyma early in the course of the disease. Microglia is the first type of cell to be activated to myelin degeneration and is actually the most eminent marker of early pathological changes. Hypothetically, complement deposits and microglial activation could be indicative of engaged clearance mechanisms from apoptotic molecular signals.

Luchinetti et al. [16] have described 4 different patterns of the pathology of strictly demyelinating lesions (apparent inflammation), based on a much greater number of patients and lesions than Barnett and Prineas. Briefly, we will mention the major characteristics of each pattern. In all the patterns, $T$ cells and macrophages are present. In pattern I, OLDs are relatively rescued and remyelination occurs. Pattern II differs from I in the presence of antibodies and complement. In pattern III, apoptosis of OLDs is the major event leading to great loss of these cells. In pattern IV, there is a great loss of OLDs without clues of apoptosis. In the same study, interheterogeneity, not intraheterogeneity is suggested without excluding the fact that a new pattern may substitute another in the course of the disease. A recent study of autopsy material from patients with established MS has described the disappearance of this heterogeneity over time and the convergence in one general mechanism of demyelination [17].

We believe that these two scientific groups are not exclusive to each other. Barnett and Prineas [18] studied acute, mostly lethal, lesions and found that their further evolution was arrested along with the demyelinating lesions, while the other group used criteria for the selection of strictly inflammatory demyelinating lesions. So, these acute lesions could easily, in time, turn out to be similar to those described by Luchinetti et al. [19]. Interestingly, the apoptosis of OLDs in the study by Barnett and Prineas and the apoptosis of OLDs in the type III pattern in the study by Luchinetti et al. both refer to plaques formed early in the course of the disease since the pattern in the study by Luchinetti et al. had a disease duration of only 2 months before biopsy or autopsy. This suggests that apoptosis of OLDs could prevail during plaque evolution in some cases early in the course of the disease. In support of this, in a recent case report of a 17-year-old woman with MS, the stereotactic biopsy of an inflammatory demyelinating lesion was compatible with pattern III and markers of oxidative stress were found [20].

Conclusively, apoptosis of OLDs may be the only initial etiopathogenic phenomenon, that rapidly (within minutes) converts into different pathogenic and histopathological patterns, resulting in heterogeneity. Finally, with chronic propagation of the disease, this heterogeneity could be lost [17].

\section{Apoptosis and Autoimmunity: The Suicide That Becomes Murder}

Rapid and effective clearance mechanisms are crucial for the prevention of autoimmune responses. Several examples of autoimmunity reactions in humans and experimental animals due to clearance defects of apoptotic cells have been presented by Roos et al. [12]. The most important association mentioned is that of rheumatoid arthritis and systemic lupus erythematosus (SLE). Many autoantigens in SLE are derived from apoptotic cells (from the surface of apoptotic cells and/or leakage) [21]. Many of these are of nuclear and cytoplasmic origin; thus, they were never exposed to the immune system, with the result that they induce polyclonal immune reactions [22]. Interestingly, many cytosolic and nuclear autoantigens appear both in MS and SLE [23-25]. Moreover, MS and SLE could coexist in the same person and the term 'lupoid sclerosis' is used to describe a patient presenting with clinical features of both MS and SLE [25].

There is also substantial evidence that many autoantigens are modified during apoptosis, so, due to conformational molecular changes, neo-epitopes emerge or cryptic epitopes are uncovered and trigger autoimmune responses. These modifications are reviewed by Rodenburg et al. [22]. We want to briefly mention that many well-known autoantigens (in SLE and rheumatoid arthritis) are phosphorylated, dephosphorylated, methylated, (de-)ubiquinated and, more interestingly, citrullinated [22].

Immunogenicity of apoptotic cells is proportional to the number of the cells, meaning that redundancy of apoptosis, in respect to clearance mechanisms, is responsible for the loss of tolerance [13]. In accordance to this finding, massive apoptosis is considered as a cause for autoimmunity. 
Conclusively, apoptosis is an important risk factor for autoimmunity because: (1) new autoantigens are exposed to immune system surveillance, (2) many of them bear novel epitopes that could easily be mistaken for foreign and (3) massive apoptosis outweighs clearance mechanisms and could lead to immune system stimulation.

\section{Post-Translational Modifications}

\section{PTMs of MBP}

It is strongly believed that all proteins encoded in the human genome and translated in the cytoplasm are chemically modified, e.g. glycosylated, phosphorylated, acetylated, etc. All these modifications are called PTMs and they are pivotal for protein folding and function. Mass spectrometry is the leading technology to study PTMs [26].

$\mathrm{MBP}$ is the major myelin protein accounting for $30 \%$ of the total protein weight in the CNS. There are 4 human isoforms of MBP in the CNS (21.5, 20.2, 18.5 and 17.2 $\mathrm{kDa}$ ) [27]. These isoforms are encoded from the MBP gene and emerge from alternative splicing of a single mRNA transcript. The MBP gene is part of a gene complex called GOLLI (Genes of OLigodendrocyte LIneage). MBP is a single polypeptide chain and a highly unfolded molecule that belongs to the 'intrinsically unstructured' proteins (IUPs), meaning that its conformation depends on the microenvironment and its association with several ligands [27]. PTMs of MBP determine its conformation and affinities with several ligands and, thus, they are the major regulators of its function. PTMs of this molecule are: $\mathrm{N}$-terminal acylation, deamidation, methylation (mono- and symmetric dimethylation of a single arginyl residue), phosphorylation, citrullination and ADP-ribosylation [26]. It is well established that phosphorylation of ser7 contributes to the stabilization of the $\beta$-structure of the molecule and methylation results in the formation of compact myelin [28].

The $18.5-\mathrm{kDa}$ isoform is the major component of myelin. It is localized in the cytoplasm and interacts with lipid molecules of the cell membrane in order to form the compact structure of major dense line, seen in electron micrographs of myelin, by apposing the cytoplasmic faces of the membrane [29]. Further microheterogeneity of the $18.5-\mathrm{kDa}$ molecule was suspected by the fact that several bands (6-8) resolved on alkaline-urea polyacrylamide gel electrophoresis (PAGE). Using CM52 cation exchange chromatography, several charge isomers are yielded, named $\mathrm{C} 1-\mathrm{C} 8$ where $\mathrm{C} 1$ or MBP-Cit0 is the least modified and most cationic, and C8 or MBP-Cit6 is the most modified and the least cationic [29]. The cause of this charge microheterogeneity is the conversion of arginine to citrulline (6 conversions from $\mathrm{C} 1$ to $\mathrm{C} 8$ molecule), reducing the charge by +1 and the mass by $1 \mathrm{Da}$ [30].

This reaction is called deimination or citrullination and is catalyzed by calcium-binding enzymes, the peptidylarginine deiminases (PADs) [30]. There are 5 genes (PADI 1, 2, 3, 4, 6) and 5 isoenzymes (PAD 1, 2, 3, 4, 6) expressed in different cells and organs [30]. PAD2 is located in the brain [30]. PAD4 can be found in CNS only when PAD4 containing leukocytes invade the brain [31].

The deimination reaction is irreversible and results in the denaturation of proteins in vitro, while in vivo it causes a looser configuration of molecular structure with functional advantages for the protein [30]. An in vivo example is apoptosis, when the cytosolic calcium concentration rises leading to activation of PAD enzymes, and to the subsequent citrullination of vimentin, which depolymerizes the molecule causing changes in the cytoskeleton [30]. Furthermore, PAD4 translocates in the nucleus and causes massive deimination of histones reducing the positive charge, thus making nucleosome more susceptible to nucleases [30]. Additionally, citrullinated MBP, because of its more open structure, favors migration of precursor OLDS and normally accounts for brain plasticity in the first years of life [30]. Not surprisingly, PAD4 is mainly located in granocytes, which live for few days and die by apoptosis with the activation of PAD4 [32].

\section{Citrullination of the MBP Molecule in MS: Biological Consequences and PAD Enzyme Studies}

A mass spectroscopy study of the MBP molecule purified by autopsy material from MS patients (vs. controls) has discovered increased citrullination of the MBP molecule in NAWM [28]. Moscarello et al. [7], using CM52 cation exchange chromatography, proved that the degree of citrullination of MBP correlates also with disease severity. C8 comprises $45 \%$ of the total MBP in MS patients, whereas in healthy and other neurological diseases (OND), the percentage is 15-20\% [7]. Myelin in MS patients has been characterized as developmentally immature, since the $\mathrm{C} 8$ charge isomer is normally increased in the first 2-4 years of life (100\% up to the age of 2 years old) and then it decreases to the level of $20 \%$ in normal adult brains. The results of immunogold labeling of cryosections of WM using anti-citrulline and anti-MBP antibodies were in accordance with the previous observations. The $\mathrm{C} 8 / \mathrm{C} 1$ ratio is also higher in MS patients. In 
support of these findings, in acute (Marburg type) MS, up to $80 \%$ of the MBP molecules have 18 out of the $19 \mathrm{Arg}$ citrullinated (MBP-Cit18) [33].

Citrullination of MBP results in less compact myelin of NAWM in MS patients. Vesicle aggregation studies indicated that the reduction of positive charge by citrullination results in less capability of the MBP molecule to aggregate and organizes the lipid in a multilayer arrangement [34]. Additionally, the density of myelin in normal human brains is higher when the $\mathrm{C} 1 / \mathrm{C} 8$ ratio is increased [35]. Structural variations in electron micrographs of protein-lipid complexes formed by incubation of citrullinated MBP with lipid monolayers of PtdSer and monosialoganglioside (GM1), have demonstrated the correlation of myelin destabilization with the degree of citrullination [36]. Similar observations have been noted with MBP-Cit18 (net charge +2) [37]. Immunogold localization of C8 in cryosections of human brain biopsies has localized C8 in the intraperiod line of myelin, whereas the other charge isomers have been found in a major dense line [38].

Citrullination of MBP results in the emergence of immunodominant epitopes. Citrullinated MBP has a more open structure and it is sensitive to cathepsin D degradation (an enzyme involved in cleavage of antigens in the antigen presenting cells) and stromelysin-1 (matrix metalloproteinase protein-3, MMP-3) [39-42]. The degree of citrullination correlates positively with the degree of catalyzed degradation [40]. Autocleavage activity of MBP, which releases the immunodominant epitopes $84-89$, has been more robust in MS, suggesting that conformational changes of the MBP molecule due to the citrullination is the major culprit [43].

PAD enzymes (and especially PAD2) are the key enzymes for deimination in CNS. PAD2 and PAD4 enzymes are increased in NAWM of MS brains [44-46]. Hypomethylation of $\mathrm{CpG}$ islands in the promoter region of the PADI2 gene by DNA demethylases seems to account for the upregulation of PAD2 in NAWM [46]. Increased deimination of histone $\mathrm{H} 3$ has also been found in MS, suggesting the translocation of PAD4 in the nucleus [44]. In addition, DNA demethylase is increased in NAWM in MS patients [47]. Methylation antagonizes the effects of citrullination [48].

\section{PTMs and Autoimmunity}

Adaptive immunity is generated by the antigen presenting cells that uptake antigens, and they present them, after degradation reactions, to effector cells (mainly immature T cells) via the MHC molecule, in an inflamma- tory context. 'Foreign' antigenic epitopes are more immunogenic than body epitopes who are usually encountered by autoreactive T cells which become deleted or anergized. PTMs contribute to autoimmunity in three major ways: (1) they escape central tolerance because they do not appear in the thymus, (2) they are implicated in the proteolytic processes that occur inside the antigen presenting cell in order to associate specific peptides to MHC molecules, and (3) they create novel untolerized epitopes (cryptic- and neo-epitopes) in the periphery by triggering conformational changes in the peptide that carries them.

A promising study by $\mathrm{Ng}$ et al. [49] has revealed that $100 \%$ of 45 randomly selected autoantigens, including MBP, demonstrate alternative splicing of their mRNA. Additionally, 70\% of the autoantigen isoform-specific regions in mRNA encode antibody binding domains, $92 \%$ encode MHC I-restricted T cell antigen epitopes and 88\% encode MHC II-restricted T cell antigen epitopes. It has been proposed that alternative splicing generates novel tolerance-breaking epitopes. Of most interest is that isoform-specific regions encode PTMs [49].

Several other reports substantiate the idea that PTMs are associated with autoimmunity. Post-translational modification of MHC-associated peptides have been found either directly by mass spectrometry or indirectly by demonstrating $\mathrm{T}$ cell recognition of such modified peptides. Engelhard et al. [50] summarized all the PTMs that relate to autoimmunity. Citrullinated epitopes (e.g. citrullinated fibrin, filaggrin, vimentin) are recognized by several antibodies seen in rheumatoid arthritis [51]. PADI4 gene polymorphisms have also been related to rheumatoid arthritis [30]. T cell responses to citrullinated MBP peptides have been found in MS patients, while citrullination of MBP epitopes triggers T cell responses in vitro $[52,53]$. However, one study did not reveal antibody responses in citrullinated forms of MBP [54].

PTMs not only fail to block procedures that are responsible for binding peptides to MHC molecules but also enhance them [50]. Deimination of arginine is an example [50]. As mentioned above, citrullination of MBP causes autocleavage degradation (digestion of itself) and renders the MBP molecule more susceptible to myelin proteases such as cathepsin D and stromelysin-1, causing the emergence of immunodominant epitopes of MS. In addition, the reduction of cationicity of MBP molecule by citrullination, causes the exposure of highly encephalitogenic epitopes of this protein in the surface of the myelin sheath and, thus, it could initiate or sustain the autoimmune procedures [55]. 


\section{Concluding Remarks}

Early changes in NAWM in MS seem to precipitate late autoimmune reactions [4-6, 14]. Some type of biological stress, such as infections, minerals, etc., should affect CNS parenchyma, causing early pathological phenomena. Autopsy studies indicate apoptosis of OLDS as an early pathological event, either directly or indirectly. Direct evidence is supported by only one study so far [6]. Indirect evidence comes from microglia activation and complement deposits, suggesting the activation of apoptotic clearance mechanisms $[6,14]$. Actually, microglia activation consists of an independent marker of biological stress [56]. The PAD4 increase in NAWM is also indicative for apoptotic mechanisms $[30,44,45]$.

Early biochemical changes have also been tracked in NAWM. Citrullination of the MBP molecule by PAD2 enzyme is increased in NAWM and it correlates with disease severity [7, 28, 33, 45]. PAD2 gene upregulation, presumably by some type of biological stress, is the most possible reason so far [46]. Interestingly, the PAD2 enzyme is overexpressed in many neurodegenerative diseases and hypoxic conditions; therefore, it could serve as an auxiliary marker of biological stress [31]. In support of that, increased citrullination of glial fibrillary acidic protein (an intermediate filament like vimentin) occurs in NAWM in secondary progressive MS patients, indicating a more generalized activation of PAD enzymes [57].

The PAD2 enzyme overexpression could be related to OLD immaturity. Citrullination of MBP is increased in the first years of life, contributing to myelin plasticity and migration of precursor OLDs [7]. PAD2 has been found elevated in immature OLDs in rats [58]. Stathmin, a protein that is expressed in progenitor OLDs during development to help migration, is increased in NAWM in MS brains [59]. Stathmin expression is enhanced in differentiated OLDs under biological stress conditions and render them more prone to apoptosis stimuli [60]. Injury of brain parenchyma causes loss of both mature and progenitors OLDs, although microglia activation due to the injury reduces mature OLD apoptosis and decreases progenitor cell survival in vitro $[59,61]$. Also, progenitor OLDs are more vulnerable to injuries such as irradiation $[62,63]$. Thus, PAD2 overexpression in NAWM could represent a switch to immaturity, in order to cope with the ensuing injury caused by the biological stress, but OLD vulnerability to apoptosis inevitably rises.

Interestingly, PAD2 and stathmin expression could be attributed to an arrest in OLD differentiation in early childhood due to unknown factor(s). Thus, OLDs with mixed phenotypes become vulnerable targets to apoptotic death due to other types of biological insults during adulthood. This is in accordance with the well-known fact that early childhood events determine susceptibility to the disease [64].

Myelin instability due to MBP citrullination is considered a cause for dying back oligodendrogliopathy (DBO) $[55,65]$. DBO is caused by failure of the cell body to support metabolically distal periaxonal processes. Vesicles and mitochondria accumulation in that region is the pathological hallmark of $\mathrm{DBO}$, causing detrimental procedures for the cell [66]. DBO has been found in 11 stereotactic brain biopsies from MS brains [67]. Myelin instability, caused by myelin associated glycoprotein depletion causes DBO, so it is very likely that MBP citrullination could have similar effects [66].

In summary, apoptosis of OLDs and citrullination of CNS proteins seem to be part of diffuse microstructural (and invisible to conventional MRI techniques), early neurodegeneration in MS. Additionally, these two procedures may represent, as markers, the yet unidentified elements of the above mentioned biological stress. They also could lead to the well-recognized inflammatory and autoimmune processes, which are the main therapy targets so far. Given the importance of early therapy in MS course, this seems more mandatory than ever.

We propose that future studies focus on the primary pathogenetic mechanisms of MS, aiming at clarifying the very early steps of the disease processes. To achieve that, patients preferably with the very first clinical manifestations, like clinically isolated syndrome, must be included. Although time and space disease criteria are provided, they are inadequate for inclusion of patients at such early stages of the disease, as epitope spreading could not mask the initial pathogenetic mechanisms [68-70]. Additionally, autopsies at the early stage of the disease can be performed only in the case of accidental death or acute fulminant disease leading to the death of the patient (Marburg's variant of MS). Stereotactic biopsies of living patients are rare and it is unethical to encourage such procedures for the sake of research. On the other hand, the rapidly improving noninvasive imaging techniques constitute a promising field for the study of early MS stages. Additionally, apoptosis of OLDs and immune responses to post-translationally modified myelin proteins at the early stages of the disease must be investigated both qualitatively and quantitatively. Demystifying the whole spectrum of these processes may lead to new horizons in MS therapeutic strategies, in the future. 


\section{References}

$\checkmark 1$ Flachenecker P: Epidemiology of neuroimmunological diseases. J Neurol 2006; 253(Suppl 5):v2-v8.

2 Becher B, Bechmann I, Greter M: Antigen presentation in autoimmunity and CNS inflammation: how $\mathrm{T}$ lymphocytes recognize the brain. J Mol Med 2006;84:532-543.

- 3 Lassmann H, Brück W, Lucchinetti CF: The immunopathology of multiple sclerosis: an overview. Brain Pathol 2007;17:210-218.

4 Filippi M, Rocca MA: MRI evidence for multiple sclerosis as a diffuse disease of the central nervous system. J Neurol 2005;252(Suppl 5):v16-v24.

5 Filippi M: Linking structural, metabolic and functional changes in multiple sclerosis. Eur J Neurol 2001;8:291-297.

6 Barnett MH, Prineas JW: Relapsing and remitting multiple sclerosis: pathology of the newly forming lesion. Ann Neurol 2004;55: 458-468.

7 Moscarello MA, Wood DD, Ackerley C, Boulias C: Myelin in multiple sclerosis is developmentally immature. J Clin Invest 1994; 94:146-154.

8 Blank M, Shiloh Y: Programs for cell death: apoptosis is only one way to go. Cell Cycle 2007;6:686-695.

-9 Cline AM, Radic MZ: Apoptosis, subcellular particles and autoimmunity. Clin Immunol 2004;112:175-182.

$\checkmark 10$ Nicholson DW, Thornberry NA: Caspases: killer proteases. Trends Biochem Sci 1997;22: 299-306.

11 Liu G, Wuy C, Wu Y, Zhao Y: Phagocytosis of apoptotic cells and immune regulation. Scand J Immunol 2006;64:1-9.

- 12 Roos A, Xu W, Castellano G, Nauta AJ, Garred P, Daha MR, van Kooten C: Mini-review: A pivotal role for innate immunity in the clearance of apoptotic cells. Eur J Immunol 2004;34:921-929.

13 Ronchetti A, Rovere P, Iezzi G, Galati G, Heltai S, Protti MP, Garancini MP, Manfredi AA, Rugarli C, Bellone M: Immunogenicity of apoptotic cells in vivo: role of antigen load, antigen presenting cells and cytokines. J Immunol 1999;163:130-136.

14 Gay FW: Early cellular events in multiple sclerosis. Intimations of an extrinsic myelinolytic antigen. Clin Neurol Neurosurg 2006; 108:234-240.

15 Barnett MH, Parratt JD, Cho ES, Prineas JW: Immunoglobulins and complement in postmortem multiple sclerosis tissue. Ann Neurol 2009;65:32-46.

16 Lucchinetti C, Bruck W, Parisi J, Scheithauer B, Rodriguez M, Lassmann H: Heterogeneity of multiple sclerosis lesions: implications for the pathogenesis of demyelination. Ann Neurol 2000;47:707-717.
17 Breij EC, Brink BP, Veerhuis R, van den Berg C, Vloet R, Yan R, Dijkstra CD, van der Valk P, Bö L: Homogeneity of active demyelinating lesions in established multiple sclerosis. Ann Neurol 2008;63:16-25.

18 Barnett MH, Prineas JW: Pathological heterogeneity in multiple sclerosis: a reflection of lesion stage? Ann Neurol 2004;56:309.

19 Lucchinetti CF, Bruck W, Lassmann H: Evidence for pathogenic heterogeneity in multiple sclerosis. Ann Neurol 2004;56:308.

20 Zeis T, Probst A, Steck AJ, Stadelmann C Brück W, Schaeren-Wiemers N: Molecular changes in white matter adjacent to an active demyelinating lesion in early multiple sclerosis. Brain Pathol 2009;19:459-466.

21 Rosen A, Casciola-Rosen L: Autoantigens as substrates for apoptotic proteases: implications for the pathogenesis of systemic autoimmune disease. Cell Death Differ 1999;6: 6-12.

22 Rodenburg RJ, Raats JM, Pruijn GJ, van Venrooij WJ: Cell death: a trigger of autoimmunity? Bioessays 2000;22:627-636.

-23 Lu F, Kalman B: Autoreactive IgG to intracellular proteins in sera of MS patients. J Neuroimmunol 1999;99:72-81.

24 Spadaro M, Amendolea MA, Mazzucconi MG, Fantozzi R, Di Lello R, Zangari P, Masala G: Autoimmunity in multiple sclerosis: study of a wide spectrum of autoantibodies. Mult Scler 1999;5:121-125.

25 Williamson RA, Burgoon MP, Owens GP, Ghausi O, Leclerc E, Firme L, Carlson S, Corboy J, Parren PW, Sanna PP, Gilden DH, Burton DR: Anti-DNA antibodies are a major component of the intrathecal $B$ cell response in multiple sclerosis. Proc Natl Acad Sci USA 2001;98:1793-1798.

26 Schweppe RE, Haydon CE, Lewis TS, Resing KA, Ahn NG: The characterization of protein post-translational modifications by mass spectrometry. Acc Chem Res 2003;36: 453-461.

27 Harauz G, Ishiyama N, Hill CM, Bates IR, Libich DS, Fares C: Myelin basic protein-diverse conformational states of an intrinsically unstructured protein and its roles in myelin assembly and multiple sclerosis. $\mathrm{Mi}$ cron 2004;35:503-542.

28 Kim JK, Mastronardi FG, Wood DD, Lubman DM, Zand R, Moscarello MA: Multiple sclerosis: an important role for post-translational modifications of myelin basic protein in pathogenesis. Mol Cell Proteomics 2003; 2:453-462.

29 Harauz G, Musse AA: A tale of two citrullines - structural and functional aspects of myelin basic protein deimination in health and disease. Neurochem Res 2007;32:137158.

-30 Gyorgy B, Toth E, Tarcsa E, Falus A, Buzas EI: Citrullination: a posttranslational modification in health and disease. Int J Biochem Cell Biol 2006;38:1662-1677.
-31 Sambandam T, Belousova M, Accaviti-Loper MA, Blanquicett C, Guercello V, Raijmakers R, Nicholas AP: Increased peptidylarginine deiminase type II in hypoxic astrocytes. Biochem Biophys Res Commun 2004;325:13241329.

-32 Liu GY, Liao YF, Chang WH, Liu CC, Hsieh MC, Hsu PC, Tsay GJ, Hung HC: Overexpression of peptidylarginine deiminase IV features in apoptosis of haematopoietic cells. Apoptosis 2006;11:183-196.

33 Wood DD, Bilbao JM, O'Connors P, Moscarello MA: Acute multiple sclerosis (Marburg type) is associated with developmentally immature myelin basic protein. Ann Neurol 1996;40:18-24.

34 Boggs JM, Rangaraj G, Koshy KM, Ackerley C, Wood DD, Moscarello MA: Highly deiminating isoform of myelin basic protein from multiple sclerosis brain causes fragmentation of lipid vesicles. J Neurosci Res 1999;57: 529-535.

35 Moscarello MA, Brady GW, Fein DB, Wood DD, Cruz TF: The role of charge microheterogeneity of basic protein in the formation and maintenance of the multilayered structure of myelin: a possible role in multiple sclerosis. J Neurosci Res 1986;15:87-99.

36 Beniac DR, Wood DD, Palaniyar N, Ottensmeyer FP, Moscarello MA, Harauz G: Cryoelectron microscopy of protein-lipid complexes of human myelin basic protein charge isomers differing in degree of citrullination. J Struct Biol 2000;129:80-95.

37 Beniac DR, Wood DD, Palaniyar N, Ottensmeyer FP, Moscarello MA, Harauz G: Marburg's variant of multiple sclerosis correlates with a less compact structure of myelin basic protein. Mol Cell Biol Res Commun 1999;1: 48-51.

-38 McLaurin J, Ackerley CA, Moscarello MA: Localization of basic proteins in human myelin. J Neurosci Res 1993;35:618-628.

-39 D'Souza CA, Moscarello MA: Differences in susceptibility of MBP charge isomers to digestion by stromelysin-1 (MMP-3) and release of an immunodominant epitope. Neurochem Res 2006;31:1045-1054.

40 Cao L, Goodin R, Wood D, Moscarello MA, Whitaker JN: Rapid release and unusual stability of immunodominant peptide 45-89 from citrullinated myelin basic protein. Biochemistry 1999;38:6157-6163.

41 Musse AA, Boggs JM, Harauz G: Deimination of membrane-bound myelin basic protein in multiple sclerosis exposes an immunodominant epitope. Proc Natl Acad Sci USA 2006; 103:4422-4427.

42 Pritzker LB, Joshi S, Gowan JJ, Harauz G, Moscarello MA: Deimination of myelin basic protein. 1. Effect of deimination of arginyl residues of myelin basic protein on its structure and susceptibility to digestion by cathepsin D. Biochemistry 2000;39:53745381. 
-43 D’Souza CA, Wood DD, She YM, Moscarello MA: Autocatalytic cleavage of myelin basic protein: an alternative to molecular mimicry. Biochemistry 2005;44:12905-12913.

-44 Mastronardi FG, Wood DD, Mei J, Raijmakers R, Tseveleki V, Dosch HM, Probert L, Casaccia-Bonnefil P, Moscarello MA: Increased citrullination of histone $\mathrm{H} 3$ in multiple sclerosis brain and animal models of demyelination: a role for tumor necrosis factor-induced peptidylarginine deiminase 4 translocation. J Neurosci 2006;26:1138711396.

-45 Wood DD, Ackerley CA, Brand B, Zhang L, Raijmakers R, Mastronardi FG, Moscarello MA: Myelin localization of peptidylarginine deiminases 2 and 4: comparison of PAD2 and PAD4 activities. Lab Invest 2008;88: 354-364.

46 Mastronardi FG, Noor A, Wood DD, Paton T, Moscarello MA: Peptidyl argininedeiminase $2 \mathrm{CpG}$ island in multiple sclerosis white matter is hypomethylated. J Neurosci Res 2007;85:2006-2016.

$\checkmark 47$ Moscarello MA, Mastronardi FG, Wood DD: The role of citrullinated proteins suggests a novel mechanism in the pathogenesis of multiple sclerosis. Neurochem Res 2007; 32:251.

-48 Pritzker LB, Joshi S, Harauz G, Moscarello MA: Deimination of myelin basic protein. 2 . Effect of methylation of MBP on its deimination by peptidylarginine deiminase. Biochemistry 2000;39:5382-5388.

-49 Ng B, Yang F, Huston DP, Yan Y, Yang Y, Xiong Z, Peterson LE, Wang H, Yang XF: Increased noncanonical splicing of autoantigen transcripts provides the structural basis for expression of untolerized epitopes. J Allergy Clin Immunol 2004;114:1463-1470.

-50 Engelhard VH, Altrich-Vanlith M, Ostankovitch M, Zarling AL: Post-translational modifications of naturally processed $\mathrm{MHC}$ binding epitopes. Curr Opin Immunol 2006; 18:92-97.

51 Zhou Z, Menard HA: Autoantigenic posttranslational modifications of proteins: does it apply to rheumatoid arthritis? Curr Opin Rheumatol 2002;14:250-253.
52 Tranquill LR, Cao L, Ling NC, Kalbacher H, Martin RM, Whitaker JN: Enhanced T cell responsiveness to citrulline-containing myelin basic protein in multiple sclerosis patients. Mult Scler 2000;6:220-225.

53 Deraos G, Chatzantoni K, Matsoukas MT, Tselios T, Deraos S, Katsara M, Papathanasopoulos P, Vynios D, Apostolopoulos V, Mouzaki A, Matsoukas J: Citrullination of linear and cyclic altered peptide ligands from myelin basic protein (MBP(87-99)) epitope elicits a Th1 polarized response by $\mathrm{T}$ cells isolated from multiple sclerosis patients: implications in triggering disease. J Med Chem 2008;51:7834-7842.

54 de Seze J, Dubucquoi S, Lefranc D, Virecoulon F, Nuez I, Dutoit V, Vermersch P, Prin L: IgG reactivity against citrullinated myelin basic protein in multiple sclerosis. J Neuroimmunol 2001;117:149-155.

55 Musse AA, Harauz G: Molecular 'negativity' may underlie multiple sclerosis: role of the myelin basic protein family in the pathogenesis of MS. Int Rev Neurobiol 2007;79:149172.

56 Gehrmann J, Matsumoto Y, Kreutzberg GW: Microglia: intrinsic immuneffector cell of the brain. Brain Res Brain Res Rev 1995;20: 269-287.

57 Nicholas AP, Sambandam T, Echols JD, Tourtellotte WW: Increased citrullinated glial fibrillary acidic protein in secondary progressive multiple sclerosis. J Comp Neurol 2004;473:128-136.

58 Akiyama K, Sakurai Y, Asou H, Senshu T: Localization of peptidylarginine deiminase type II in a stage-specific immature oligodendrocyte from rat cerebral hemisphere. Neurosci Lett 1999;274:53-55.

59 Miller BA, Crum JM, Tovar CA, Ferguson AR, Bresnahan JC, Beattie MS: Developmental stage of oligodendrocytes determines their response to activated microglia in vitro. J Neuroinflammation 2007;4:28.

60 Liu A, Stadelmann C, Moscarello M, Bruck W, Sobel A, Mastronardi FG, Casaccia-Bonnefil P: Expression of stathmin, a developmentally controlled cytoskeleton-regulating molecule, in demyelinating disorders. J Neurosci 2005;25:737-747.

61 Wolswijk G: Oligodendrocyte survival, loss and birth in lesions of chronic-stage multiple sclerosis. Brain 2000;123:105-115.
62 Fukuda A, Fukuda H, Swanpalmer J, Hertzman S, Lannering B, Marky I, Björk-Eriksson T, Blomgren K: Age-dependent sensitivity of the developing brain to irradiation is correlated with the number and vulnerability of progenitor cells. J Neurochem 2005;92: 569-584.

63 Fragoso G, Martínez-Bermúdez AK, Liu HN, Khorchid A, Chemtob S, Mushynski WE, Almazan G: Developmental differences in HO-induced oligodendrocyte cell death: role of glutathione, mitogen-activated protein kinases and caspase 3. J Neurochem 2004;90:392-404.

64 Pugliatti M, Riise T, Sotgiu MA, Satta WM, Sotgiu S, Pirastru MI, Rosati G: Evidence of early childhood as the susceptibility period in multiple sclerosis: space-time cluster analysis in a Sardinian population. Am J Epidemiol 2006; 164:326-333.

65 Mastronardi FG, Moscarello MA: Molecules affecting myelin stability: a novel hypothesis regarding the pathogenesis of multiple sclerosis. J Neurosci Res 2005;80:301-308.

-66 Lassmann H, Bartsch U, Montag D, Schachner M: Dying-back oligodendrogliopathy: a late sequel of myelin-associated glycoprotein deficiency. Glia 1997;19:104-110.

67 Rodriguez M, Scheithauer BW, Forbes G, Kelly PJ: Oligodendrocyte injury is an early event in lesions of multiple sclerosis. Mayo Clin Proc 1993;68:627-636.

68 Davies S, Nicholson T, Laura M, Giovannoni G, Altmann DM: Spread of T lymphocyte immune responses to myelin epitopes with duration of multiple sclerosis. J Neuropathol Exp Neurol 2005;64:371-377.

69 Goebels N, Hofstetter H, Schmidt S, Brunner C, Wekerle H, Hohlfeld R: Repertoire dynamics of autoreactive $\mathrm{T}$ cells in multiple sclerosis patients and healthy subjects: epitope spreading versus clonal persistence. Brain 2000;123:508-518.

70 McDonald WI, Compston A, Edan G, Goodkin D, Hartung HP, Lublin FD, McFarland $\mathrm{HF}$, Paty DW, Polman CH, Reingold SC, Sandberg-Wollheim M, Sibley W, Thompson A, van den Noort S, Weinshenker BY, Wolinsky JS: Recommended diagnostic criteria for multiple sclerosis: guidelines from the International Panel on the Diagnosis of Multiple Sclerosis. Ann Neurol 2001;50:121-127. 